\title{
A Respeito das Citações dos "Arquivos"
}

editorial

O

AMADURECIMENTO DOS ABE\&M como a revista científica dos endocrinologistas brasileiros é uma realidade incontestável. Sua leitura tem servido não somente para subsidiar diagnósticos e condutas do clínico de consultório, como também para trazer revisões e novos conhecimentos sobre a fisiologia e a fisiopatologia das doenças endócrinas para o recémformado e mesmo para o já especialista na área.

Não apenas isto, mas o arquivamento da produção científica nacional tem sido um processo gradual e constante, com muito mais autores nacionais dando preferência aos ABE\&M para apresentar e divulgar seus dados.

A média de submissão de artigos para possível publicação na revista vem se elevando de maneira consistente ao longo dos últimos anos. De uma média anual estável nos anos 90, de 50-60 submissões, tivemos no ano passado mais de 80 trabalhos e, em especial em 2002 - computados os dados até o início de outubro (portanto $75 \%$ do total previsto) -, já recebemos 85 novos artigos. Deste total, temos tido a oportunidade de aproveitar 85 a $90 \%$ do material, mantendo uma média de rejeição pelo Conselho Editorial de 10 a $15 \%$ ao ano.

Creio que não somente o Conselho Editorial, mas também uma substancial parcela dos membros da Comissão de Revisores e outros colaboradores, são testemunhas da enorme melhoria de qualidade dos artigos atualmente submetidos. Passamos, felizmente, da fase da ingenuidade de relatos de caso simplórios, sem qualquer contribuição científica maior, revisões despretensiosas de biblioteca e artigos nem tão originais, mais voltados a apuração retrospectiva de casuística, para um material que na maioria das vezes prima pelo cuidado da apresentação, pela atenção com os objetivos e desenho da pesquisa, e pela análise e discussão ordenada e lógica. Faltam-nos, ainda, trabalhos prospectivos bem delineados, com objetivos mais precisos e pertinentes e com desenho, análise e interpretação de caráter profissional. Artigos com estas características de qualidade, produzidos pelos excelentes centros de pesquisa e cursos de pós-graduação em endocrinologia de todo o país, provavelmente existem às centenas, mas certamente continuam sendo direcionados para revistas de maior visibilidade internacional. É, portanto, apenas uma questão de tempo para que possamos começar a disputá-los com as congêneres estrangeiras!

Critica-se, daqui e dali, que os trabalhos publicados nos Arquivos não são citados com freqüência, nem ao menos pelos próprios autores em publicações subseqüentes. Parecem, muitas vezes, passar despercebidos. Outro dia, durante uma defesa de tese, um examinador comentou sobre a ausência, na lista de referências do trabalho, de um artigo de sua autoria publicado nos Arquivos, que antecedia em originalidade o trabalho do candidato!

Não existem dados estatísticos suficientemente disponíveis para analisar tais fatos, mas dentro dos artigos publicados na própria revista, este número não tem sido nem desprezível nem portentoso. Vejamos:

\author{
Disciplina de Endocrinologia, \\ Departamento de Medicina, \\ UNIFESP/EPM \\ Editor-chefe, $A B E \mathcal{E} M$
}


Analisando apenas a última década (19922002), observamos um crescimento anual tanto no número de artigos publicados (de 30 para 84), como de citações (referências) bibliográficas (de 737 para 3.800 ), tendo-se elevado também (curiosamente!) o número de citações por artigo publicado (de 25 para 46). Entretanto, o total de citações de artigos dos ABE\&M na própria revista elevou-se proporcionalmente menos (de 24 para 52 por ano), o mesmo acontecendo com o total de citações de outras revistas nacionais nos ABE\&M (de 45 para 72). Assim, a percentagem de citações da nossa e de outras revistas nacionais nos $\mathrm{ABE} \& \mathrm{M}$ variou de 1,0 a $3,3 \%$ (mediana de $1,7 \%$ ) e de 2,4 a $6,3 \%$ (mediana de $3,1 \%$ ), respectivamente. Isso resulta na média de uma citação dos Arquivos em cada dois artigos $(0,5 \%)$ e de quase duas citações de outras revistas nacionais em cada artigo publicado nos $\mathrm{ABE} \& M(1,9 \%)$. Este porcentual não parece assim tão convincente, mas vejamos adiante.

Uma rápida consulta à seção de estatística do site da SciELO (www.scielo.org) mostra que do total de citações nos ABE\&M durante o ano de 2001 (2.692 citações em 72 artigos das 6 edições regulares) e 2002 ( 1.425 citações em 40 artigos das 3 primeiras edições do ano), respectivamente $1,5 \%$ e $2,6 \%$ foram de artigos da própria revista. Levando-se em conta apenas estes últimos 2 anos (e apenas o primeiro semestre de 2002), tem-se a impressão que a porcentagem melhorou: de uma média de 40 citações em cada artigo publicado nos ABE\&M, pelo menos uma delas era da própria revista, e não necessariamente do próprio autor (auto-referência).

Constata-se, também, que a enorme maioria das citações é de revistas estrangeiras, tendo-se citado também esporadicamente as brasileiras: Braz J Med Biol Res, Rev Assoc Med Bras, Arq Bras Cardiol e Rev Saúde Pública.

Por outro lado, o interesse do "internauta" por artigos dos $\mathrm{ABE} \& \mathrm{M}$ torna-se aparente nestes dados: cada uma das 6 edições de 2001 foi visitada (medida pelo acesso ao índice/sumário, resumo/abstracts ou artigos $\mathrm{em} \mathrm{html/pdf)} \mathrm{mais} \mathrm{de} 5.000$ vezes desde 25/06/01 até $20 / 10 / 02$. Somente o vol. 45/5 (Out. 2001) foi visitado 7.393 vezes. Onze artigos específicos foram requisitados mais de 500 vezes, e os artigos de M.A.S. Cabrera e W. Jacob Filho (ABEM 2001; 45/5:494-501), R.L.O. Brasil et al (ABEM 2001; 45/2:134-140) e M. Mancini (ABEM 2001; 45/6:484-608) foram visitados 1.496, 1.424 e 1.163 vezes, respectivamente. Nada mal!

Isto tudo porque temos incorporados ao banco de dados SciELO apenas as 6 edições de 2001 e as 3 primeiras de 2002, e assim mesmo, disponibilizadas apenas a partir de Junho de 2001. Entretanto, todas as edições de 1998, 1999 e 2000 já foram compiladas e preparadas para disponibilização ainda este ano. Futuramente, se o tempo e o orçamento permitirem, poderemos disponibilizar na SciELO todas as edições passadas dos ABE\&M, desde 1951.

Por tudo isso, é aceitável que os Arquivos não apresentem ainda o status de uma revista internacional, com seus festejados (mas improdutivos) índices de impacto, de citações, etc. Mas nossas próprias instituições de apoio e fomento à pesquisa cumprem um papel muitas vezes paradoxal ao apoiar financeiramente nossas melhores revistas nacionais, os Arquivos incluídos, e ao mesmo tempo, para pontuar e graduar investigadores candidatos a bolsas e auxílios, valorizarem apenas suas publicações internacionais de alto impacto (ISI, Medline, etc). Por quê não prestigiar neste aspecto as próprias revistas nacionais que estão sendo apoiadas financeiramente? $\mathrm{O}$ que mais é necessário para uma publicação como os Arquivos, ou tantas outras nacionais em condições semelhantes, serem elevadas à posição de revistas classe $\mathrm{A}$, para efeito do currículo de investigadores? Somos certificados como de ótima qualidade pelos melhores parâmetros (e indexadores) nacionais: BIREME, SciELO, FAPESP, CAPES e CNPq. Será que é preciso algo mais, não explicitamente solicitado? Por que um artigo publicado nos Arquivos, após ter passado pelo crivo zeloso e, às vezes até extremamente rigoroso, de nossos excelentes pareceristas de todo o país, não merece ser considerado do mesmo padrão, por exemplo, de um Journal of Endocrinological Investigation, ou um Journal of Pediatric Endocrinology and Metabolism, do The Endocrinologist, ou de tantos outros periódicos internacionais da mesma estatura?

Fôssemos mais valorizados aqui mesmo entre nosso pares, deixando de lado a ambição, a docilidade ou a subserviência científica às revistas estrangeiras, nem sempre superiores e de mérito científico até discutível, e talvez estivéssemos sendo aquinhoados com um maior número de contribuições de melhor qualidade, conforme falava no início.

Por mais que recomende a vários interlocutores para que batalhem em suas áreas para maior visibilização da nossa revista, continuo ouvindo o interminável bordão: "Por que os $\mathrm{ABE} \& \mathrm{M}$ não são indexados?"

A resposta é sempre a mesma: "Serão, se investirmos mais neles! Serão, se nos orgulharmos deles! Serão, se deixarmos de lado a obsessão de querer publicar apenas no exterior! Serão, se formos incentivados e valorizados pelas nossas próprias instituições promovedoras de ciência!" 